\title{
Predicting the Future of Computers in Schools - A Reflection Paper?
}

\author{
Richard Taylor \\ International Baccalaureate Organisation, Cardiff, UK \\ richard.taylor@ibo.org
}

\begin{abstract}
Over the last 25 years advances in Information and Communication Technologies (ICTs) have led to significant changes in the way that computers ${ }^{1}$ are used within an educational context. As schools in many ways reflect a microcosm of society, one consequence for the school community is that the relationship between the computers and the computer users has become increasingly complex. There has been a blurring of the traditional clearly defined boundaries, not only between home and school computer use, but also within schools in the way that teaching and learning are carried out. This blurring may be attributed to many factors, but the continuing miniaturisation, portability and ubiquity of the computer itself is probably the most important. For many students the computer, as well as being an obligatory fashion accessory, is seen as indispensable. The thought of having to function without a computer is something for many students is hard to envisage. The only certainty for students, teachers and school managers is the continuous evolution of computers will lead to a constantly changing digital landscape.
\end{abstract}

Keywords: Computer, convergence, ubiquitous, ethical norms, behavioural norms.

\section{Computers in Schools - Case Studies}

In such an ever-changing landscape, school managers ${ }^{2}$ will need to be aware of both the physical environment related to the computer and network infrastructure as well as the wider ranging social and ethical impacts related to computer use. They will need coherent strategies to harness the benefits that computers bring and to minimise any potential problems that may result. This is something that has not always been done successfully in the past.

1 Computers are used as a generic term to include any digital device such as a desktop personal computer, laptop, tablet or mobile device. The software and platforms that are used alongside computers are included within this generic term.

2 The term manager is used to refer to senior managers (school administrator in the United States of America (USA)). Within a school managers can exist at a range of levels from the classroom teacher who will manage the use of computers within the classroom, to departmental or faculty heads who will manage the teachers and computer use at a departmental level and senior managers. 
The advances in computers have impacted on schools in a number of ways. These increasing capabilities that result from upgrading the computers every few years have led to the expansion and further development of the network infrastructure, the introduction of new software as well as changes in curriculum development and pedagogy to utilise these new opportunities. However, this increasing usage of computers can be a 'double-edged sword'. While computers can provide opportunities, each of these changes usually requires professional development for staff and may inadvertently shape behavioural and ethical norms. One example in the United Kingdom (UK) is the use of statistical packages such as a School Information Management System (SIMS), introduced during the 1990s, to track the progress of students. While in some ways SIMS can provide significantly more information about student performance, it may have unintentional longer term effects; the over-reliance of a data driven approach in the performance management of teachers, and a modification of pedagogy leading to the compartmentalisation of learning to ensure the meeting of short term targets at the expense of allowing the students to develop a holistic subject knowledge.

The mid 1970s saw a drastic change in the use of computers in schools. As the cost of personal computers (PCs) became increasingly affordable, increasing numbers were purchased. By the early 1980s many managers could see the potential benefits that computers could bring, for example purchasing the BBC Micro for tasks such as data logging in subjects like Science and Geography or to enable the introduction of Computer Science. Throughout the 1980s computers became widespread across schools as their capabilities continued to increase and their relative cost continued to decrease. One result was the development of a small number of classrooms that provided each student with sole access to a networked computer for duration of the lesson; a dedicated computer room.

By the mid-1990s there was a realisation by managers that computers could be included in whole school strategies that extended beyond a few dedicated computer rooms supported by small clusters ${ }^{3}$ or individual computers scattered across the school. These strategies included becoming a laptop school, or implementing 1:1 (one computer per child) schemes or Bring Your Own Device (BYOD) / Bring Your Own Technology (BYOT). The aim of these strategies was to increase the availability of computers for students, with the ultimate goal of providing every student with continuous access to a computer such as an $\mathrm{Pad}^{\mathrm{TM}}$, tablet or laptop.

Carey Baptist School (Melbourne, Australia) ${ }^{4}$ was a pioneer among laptop schools. In the mid-1990s a decision to introduce one laptop per student was based on the potential educational benefits from allowing each student continuous access to a laptop computer. There were also other factors that lay behind this decision such as recognising the marketing potential of introducing the laptop initiative in a highly competitive marketplace with many fee paying schools within a few kilometres of each other, as well as a relatively affluent parent community that would enable, if necessary, the costs of implementation being shared between the school and the

3 Clusters refers to a small numbers of computers, usually about 5, that were located in a classroom to assist with the teaching and learning that students could use as and when required.

4 Information provided by Mike Fitzpatrick, Carey Baptist School, Melbourne, Australia. 
parents to ensure each student had access to a laptop. However, this scheme was not straightforward as it required an intensive and protracted staff training programme (estimated to be at least 8 years before the laptops became fully integrated into daily teaching across the whole school) and the purchasing of a sizable number of computers to effectively create the critical mass for the scheme to succeed. In addition to the purchase of computers, other hardware was purchased such as data projectors to supplement the use of laptops, the school IT network infrastructure was upgraded providing access to the Internet from every classroom through Wi-Fi. A significant proportion of resources were also allocated to create a dedicated IT Support Team whose sole role was to the support all members of the school community without any responsibility for the teaching of the students.

As computers have become increasingly less expensive and portable, other schools have introduced 1:1 policies. Some 1:1 policies have been made possible by collaboration between the school, such as Nan Chau Primary School (Singapore) which has teamed up in 2012 with Microsoft and Qualcomm Incorporated to create a $21^{\text {st }}$ century classroom using smartphones (Tech\&Learning International 2012). It provides a learning environment accessible to its 350 third grade students as well as staff and parents. Staff training has been provided through the National Institute of Education of Singapore to ensure a successful implementation of the policy. Other schools such as Essa Academy in the UK market themselves as iPad schools where every teacher and student uses an iPad rather than traditional pen and paper (Muffett 2013). Like Carey Baptist School, these schemes rely on significant investments in infrastructure, staff training and parental "buy-in" and the benefits of this intensive use of computers may take a number of years to reach fruition.

Other schools, such as Westwood High School (South Carolina, USA) have taken a different approach. Since 2012 Westwood has mixed 1:1 and BYOD policies. "We have a system that is 1:1 take-home. That requires parents to pay a self-insurance fee each year to cover the cost of repairs for damages. For parents who don't want to pay the fee, we offer a daily checkout option. We also allow students to bring their own devices, provided they run Google Chrome. We use Google Apps for Education and help students set up their Google Drive Offline so they can work on projects at home without internet access" (Coulter 2013).

Unlike laptop and 1:1 initiatives, the decision to use BYOD to ensure the intensive use of computers is one that may reflect the ability of schools to raise the necessary capital; the average cost of a tablet in 2012 was about \$US200. In the UK, in a survey carried out by the British Educational Suppliers Association (BESO) between 50\% $80 \%$ of schools indicated they would be prepared to implement some form of BYOD policy (Ghosh 2013). Although this approach would enable students to have constant access to computers and not overstretch school budgets, it does raise significant questions about management of the school network and the computers themselves. With a more decentralised BYOD approach come potentially significant compatibility, appropriate use, ownership and ultimately trust issues which may not have been fully investigated in the initial implementation of the BYOD scheme. 


\section{Computers in Schools - A Blurring of the Boundaries}

The delineation of the computer-based environment within and beyond schools is becoming more and more blurred. In the early 1990s, many homes in the UK had access to a computer but not to the Internet. It would not be until 2000 that $25 \%$ of the population has Internet access. Throughout the 1990s computers were used in designated spaces such as in the home or at school to provide additional skills, for example being able to proficiently use word processing, spreadsheet, presentation, data logging and database software to complement learning activities. Any transfer of information between the home and school computers would have been on a floppy disk. Today, the school student exists in a networked world, (Wenmoth 2013): the "cloud" acts as the mechanism to ensure the continuity of access to resources and ubiquitous use of computers. Some schools such as United World College (Singapore) have since 2011 implemented cloud storage strategies, such as Google Drive. This cloud-based approach could be used to support laptop, 1:1 or BYOD strategies.

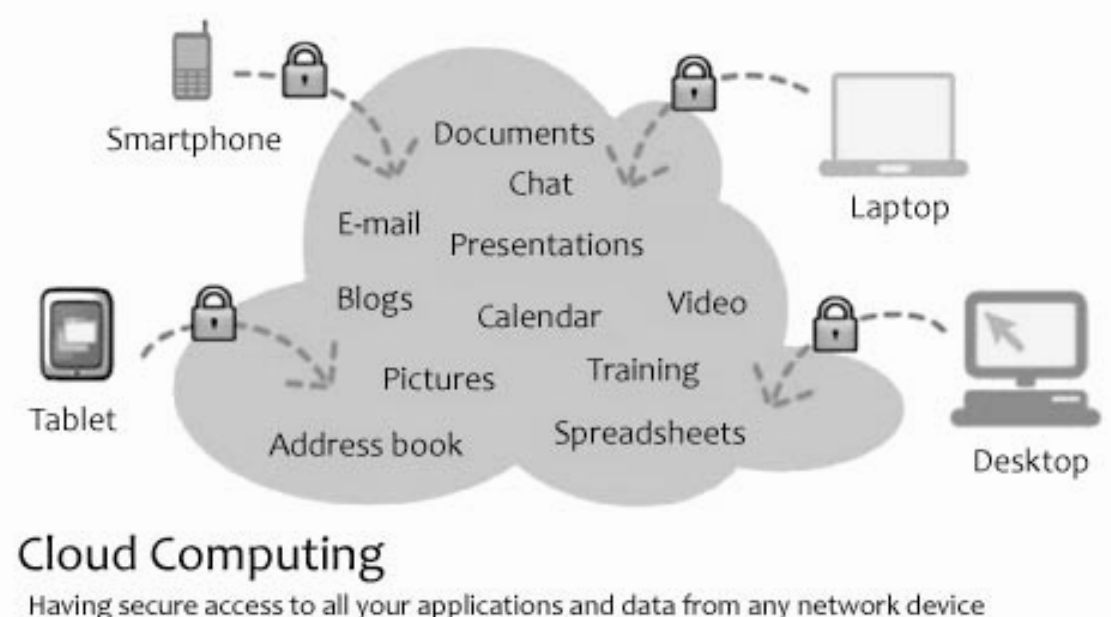

Fig. 1. A representation of cloud computing environment that many school students use (Wikipedia 2011)

This ubiquitous use of computers in a networked world is also represented in the Bradley Convergence Model, in particular in the life role of the individual. The model focuses on the convergence and integration for people through the technology which is becoming increasingly ubiquitous, the different roles of people such as their private or public role, their life environment which may be home or at work and the effects of increasing globalisation which may shape their work patterns, values and norms (Bradley 2010). This merging of roles, as illustrated in Figure 1 above and the image below, encapsulates the problems that may arise when developing school policies 
linked to contemporary computer use. In many cases it is almost impossible to distinguish whether the computer is being used for school work, for gathering images for the writing up of field work outside the classroom on return to the classroom, for example, from a museum, or for social purposes.

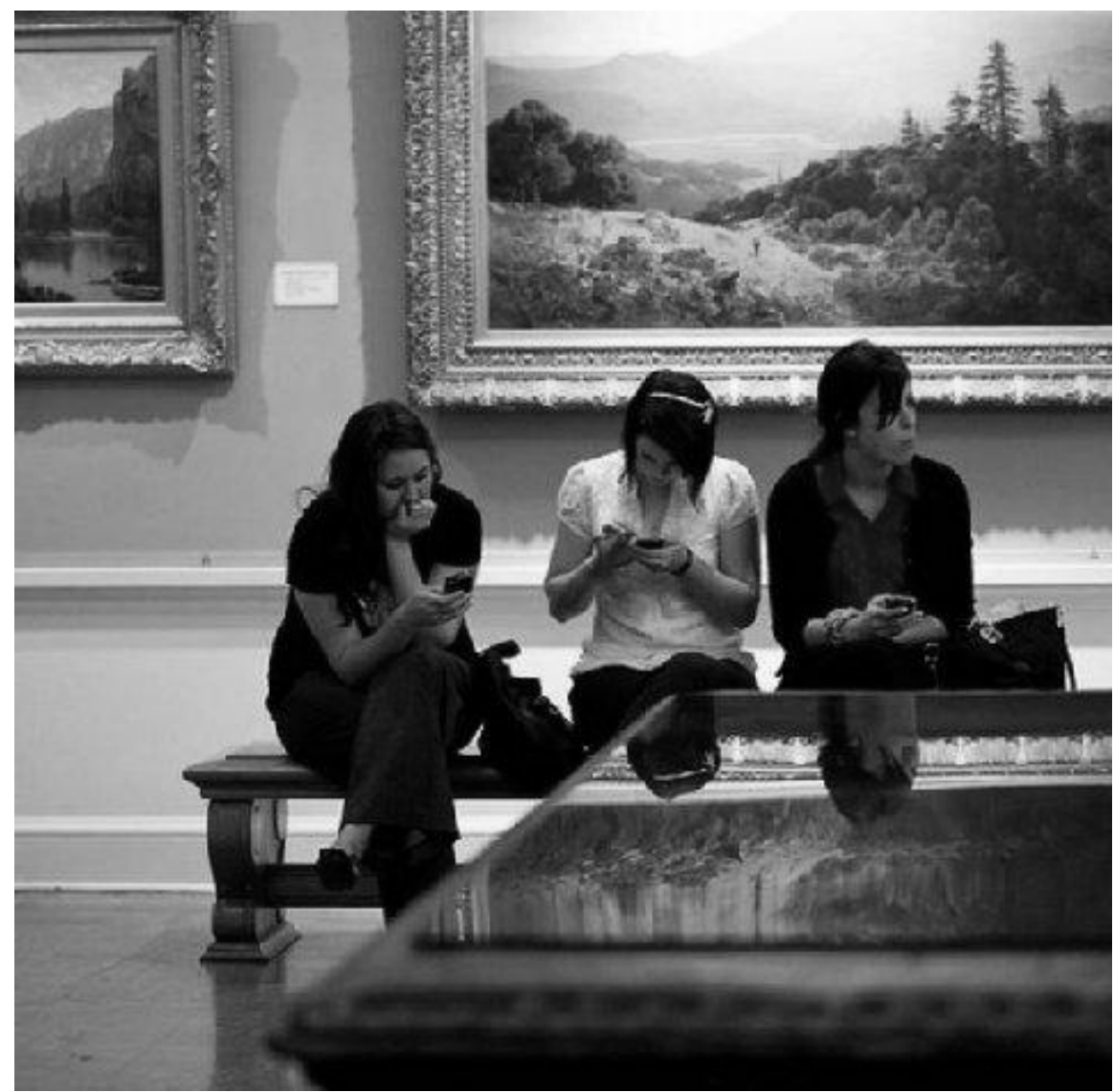

Fig. 2. A museum visit: educational or social use of computers? ${ }^{5}$

\section{The School as a Digital Society - Developing New Strategies}

While many schools have seen the use of computers as a mechanism to support the digital citizenship (people who use IT systems extensively) of the students and teachers, BYOD schools may extend digital citizenship into the development of a digital society. Kwon et al (2013) define this as being when the "social and cultural impact of digitalization has increased to a point where it cannot be separated from

\footnotetext{
${ }^{5}$ Photo used courtesy of Gunilla Bradley.
} 
daily lives of citizens". A digital society, or digital school, is characterised by three cultures: the digital tools which allow humans to maintain his/her social life in the digital society and considered as the ground for other elements of the digital culture, the digital values which form a belief system that provides meanings or goals for human behaviours or social activities in the digital society and the digital norms which represents normative procedures and rules that are socially acknowledged in carrying out digital activities. (Kwon et al 2013). The culture of tools, which equates to the acquisition of computers, may be easier and quicker to achieve than the other two elements, those of the values and norms.

With such profound changes to computers and the digital landscape occurring so rapidly, many managers have struggled to adapt their strategies accordingly. A prerequisite for the successful implementation of BYOD policies is manager readiness: "in many cases managers in schools will to ensure they remain up to date with their understanding of role of technology and how this will be reflected through school policies, pedagogical practices and change management as their ICT resources will be undergoing an almost constant evolution" (Kelly 2013). However, these disparities between the manager's understanding of the role of technology and the nature of the digital landscape they exist within are not a recent concern. Many "managers do not include staff development in the equation, instead they provide programs that do little more than ensure that teachers are able to unjam the printer or use one piece of canned instructional software" (Stager 1995). Therefore in the intervening 18 years, rather than reducing these disparities, they appear to be increasing.

If managers are not able to understand the implications of the changing digital landscape, the rapid evolution and proliferation of computers may outstrip the capabilities of the school's infrastructure. This may result in technical problems for both teachers and students. The managers also face a range of technical, social and ethical issues when the same computer is used by the student or teacher in schools, at home and socially. This constant use of computers is also leading to intended or unintended changes in the behavioural norms of the computer user. Managers need to decide to what extent they accept that the ubiquitous nature of computers is leading to ethical and behavioural changes, for example the perception of privacy being less important for students, 'the Facebook generation', and how the school will need to adapt their acceptable computer use policies accordingly.

Many schools are already struggling to formulate appropriate computer use policies as almost all students carry cell (mobile) phones and many use them during lessons. One teacher in the United States (US) noted that its managers have already adapted their cell phone policy to address this issue: "School cell phone (electronic device) policy changed this year. They can only be used before school, during lunch, and after school. It seems too many students were busy texting and were tardy to class. I do like the fact that students are not tempted to pull phones out of their pockets/purses/backpacks during class anymore 6 ." However, if the school decides to implement a BYOD policy, this will require a significant re-evaluation of this type of policy and a re-education of students about the appropriate use of cell phones. It is possible that this dash towards technology may have unexpected results and not lead to the desired outcomes.

6 Information provided by Carol Mathis, St Petersburg High School, Florida, US. 
There is also the risk of managers being "seduced" by technology as they attempt to enable the school to keep pace with the advances in computers. An alternative approach, the slow tech approach, is based on the premise that "society has been seduced by a rapid pace of development of ICT, progressively celebrated year on year for its growing speed and power". For society in general, and in this case for school managers, they may need to reflect on "a new way of thinking about ICT in the future: a slower, more careful, more considered, and more ethical manner; a slow tech approach" (Whitehouse and Patrignani 2013).

A key role of schools is to prepare their students to act as informed citizens in a digital world so managers must decide to what extent they wish to reflect the changing nature of computer use in society. These changing patterns of use are leading to an evolution of new behavioural norms. These include the need for immediate gratification (an almost instantaneous response to a call, text or tweet), the development of a new lexicon that include terms such as 'Big Data', lol, folksonomies, and verbs such as 'to Google'. Managers must determine the extent to which these changes should be incorporated into the formal and informal curriculum.

Furthermore, all societies experience inequalities. They face difficult decisions in determining what can be considered as an acceptable level of inequality between citizens. For schools the poorly managed implementation of strategies such as becoming a laptop, iPad, 1:1 or BYOD School may unknowingly exacerbate these inequalities. For the school to ensure its transition to an effective digital society, it is not enough to simply increase the provision of computers. Digital values and digital norms must also be addressed.

\section{Towards the Future: The Difficult Decisions Ahead}

If the boundaries between students' homes, schools and leisure lives become so indistinct, the traditional home / school model, and the policies and procedures associated with computer use will need to be constantly updated. In 10 years time, the role of the computer will most probably be as the facilitating device that enables students and teachers to remain constantly part of a networked world. In such a rapidly evolving digital landscape it is almost impossible to envisage what computers will be like in 2024, perhaps all students will be wearing Google Goggles ${ }^{\mathrm{TM}}$. It is almost inevitable that if the continued rate of the evolution of computers remains unchecked, schools will always be playing catch-up with any policies linked to computer procurement and usage. Alternatively, after so much change, perhaps a period of reflection will take place with managers adopting the slow tech approach.

Acknowledgements. Mike Fitzpatrick and Carol Mathis for sharing their thoughts and experiences from their respective schools.

Gunilla Bradley for the image from the museum.

Sandra Stark and Diane Whitehouse for their feedback during the authoring of this text.

\section{References}

1. BBC News Channel. Superpower: Visualising the Internet (2013), http: / / news.bbc.co.uk/1/hi/technology/8552410.stm (last accessed December 23, 2013) 
2. Bradley, G.: The Convergence Theory on ICT, Society and Human Beings - towards the Good ICT society (2010), http://www.triple-c.at/index.php/triplec/ article/download/170/186 (last accessed October 7, 2013)

3. Bradley, G.: The Convergence Theory on ICT, Society and Human Beings - towards the Good ICT society. In: Kommers, P. (ed.) Proceedings of IADIS multi-Conference on ICT Society and Human Being, Prague, Keynote address (2013)

4. Coulter, L., et al.: Have any of you had a BYOD or 1 to 1 initiative in your districts whereby parents wanted to opt out? If so, were teachers at your school willing to provide alternative assignments? (2013),

http: / / www . Iinkedin. com/groupItem?view=\&gid=2811\&type=member \&item $=270733219 \&$ comment $I D=162270305 \&$ report . success $=8 \mathrm{ULbKYXO} 6$ NDvmoK7o030UNOYGZKrvdhBhypZ_w8EpQrrQI-

BBjkmXwkEOwBjLE28YYDIXCYEO7_TA_giuRN\#COmme

(last accessed September 26, 2013)

5. Ghosh, S.: Schools warm up to BYOD for tablets (2013),

http: / /www.pcpro.co.uk/news/education/382006/

schools-warm-up-to-byod-for-tablets (last accessed October 7, 2013)

6. Kelly, A.: What are the biggest challenges facing BYOD and BYOT in education? (2013), http: / /www. naace.co.uk/byoddiscussion (last accessed October 7, 2013)

7. Kwon, M., et al.: Index development and application for measuring the level of digital culture. In: Kommers, P. (ed.) Proceedings of IADIS Multi-Conference on ICT Society and Human Beings, Prague, pp. 88-95 (2013)

8. Murdock, E.: History, the History of Computers, and the History of Computers in Education (2007), http://www.csulb.edu/ murdock/histofcs.html (last accessed November 25, 2013)

9. Muffett, T.: Essa Academy: Bookless school where everyone has iPad (2013), http://www.bbc.co.uk/news/education-20930195 (last accessed October 7, 2013)

10. Patrignani, N., Whitehouse, D.: From slow food to slow tech, a reflection paper. In: Kommers, P. (ed.) Proceedings of IADIS multi-Conference on ICT Society and Human Beings, Prague, pp. 160-164 (2013)

11. Stager, G.: Laptop schools lead the way in professional development. Educational Leadership 53(2), 78-81 (1995),

http: / /www. ascd.org/publications/educational-

leadership/oct95/vol53/num02 (last accessed November 25, 2013)

12. Tech\&Learning International. Singapore primary school launches $3 \mathrm{G}$ smartphone initiative (2012),

http: / /www . techlearning. com/Default. aspx? tabid=67\&EntryId=40 94\#disqus_thread (last accessed October 7, 2013)

13. The Journal. Computers in Education (1997), http: / / thejournal.com/Articles/1997/06/01/Computers-inEducation-A-Brief-History . aspx? Page=4 (last accessed December 23, 2013)

14. Wenmoth, D.: The emerging paradigm (2013), http://blog.core-ed.org/derek/2013/09/ learning-in-a-networked-world.html (last accessed October 7, 2013)

15. Wikipedia. Cloud Computing (July 4, 2011), http://en.wikipedia.org/wiki/File:Cloud_applications.jpg (last accessed October 7, 2011) 